\title{
Technical

\section{Enviromental behavior of steel beams embedded in concrete under static loads}

\author{
Ashkan Khoda Bandehlou ${ }^{1 *}$ and Reza Shokri Soltanabadi² \\ ${ }^{1}$ Doctor Of Philosophy of Technical Sciences, Faculty Of Engineering, Civil Engineering Department, Urmia \\ Branch, Islamic Azad University, Urmia, Iran \\ ${ }^{2}$ Ph.D. Student Of Civil Engineering-Structure, Faculty of Engineering, Civil Engineering Department, Urmia \\ Branch, Islamic Azad University, Urmia, Iran
}

\begin{abstract}
In this article environmental behavior of steel beams embedded in concrete under static loads was investigated. The obtained experimental results were compared for precision of the sample configuration of a three-dimensional finite element model. In this study, for modeling concrete, Concrete Damaged Plasticity was used. The analytical method used in this study for explicit nonlinear dynamic analysis Dynamic Explicit is selected. In contrast, in samples with a ratio of 0.5 steel flange width, usually bending failure were observed.
\end{abstract}

KEY WORDS: MIXED BEAMS, FLEXURAL BEHAVIOR, STATIC LOADING, FINITE ELEMENT METHOD.

\section{INTRODUCTION}

Analytical studies were conducted, including the members of the Security, by Spacone and El-Tawilin 2004. In this study, nonlinear analysis steel-concrete composite structures were investigated. Another study by Camps et al., (2017) has analyzed flexural behavior of composite beams with deformable connection. How the tensions in the interface of concrete and steel sections and increase ductility and impact assessed concrete creep and shrinkage behavior of the composite was investigated. Another

\section{ARTICLE INFORMATION:}

Corresponding Authors: ashkan72@rambler.ru Received $12^{\text {th }}$ Sep, 2018

Accepted after revision $19^{\text {rd }}$ Nov, 2018

BBRC Print ISSN: 0974-6455

Online ISSN: 2321-4007 CODEN: USA BBRCBA Thomson Reuters ISI ESC / Clarivate Analytics USA

Mono of Clarivate Analytics and Crossref Indexed Journal Mono of CR

NAAS Journal Score 2018: 4.31 SJIF 2017: 4.196

- A Society of Science and Nature Publication, Bhopal India 2018. All rights reserved.

Online Contents Available at: http//www.bbrc.in/

DOI: $10.21786 / \mathrm{bbrc} / 11.4 / 13$ study evaluated the short beam strength composite columns by Mirza and Skranek which was conducted in 1991. Other research studies on prestressed beams have been combined in this research, which are based on analytically studied proposals for the design of this type of beam bending is presented, (Zhao and Li 2017).

The survey in 1989 was conducted by Saadatmanesh and colleagues. The use of prestressed steel beams for composite steel - concrete increases the bearing capacity of steel beams to the current stage and also increases the resistance of the composite section final. At the same 
time prestressing tension flange reduced the amplitude cyclic stress and improve fatigue resistance.In another study conducted in 2005 by Ellbody and Young, shear bond strength impact and efficiency in composite beams has been investigated. Another study under the title of ultimate strength of continuous composite beams under combined bending and cutting was done by Liang et al. Based on numerical results, a new design model based on vertical shear resistance and interaction Anchor cutting the continuous composite beams have been proposed. The proposed design models were compared with experimental results and good agreement is shown (Goldston, et al. 2016 and Ongpenget al.2018).

Zhao and Li in 2008, conducted a numerical study in conjunction with a new way to create continuity in composite beams. The flow of steel beam to reduce the local rigidity and lead to brittle fracture the concrete. In 2005, Lam and his colleagues evaluated the behavior of shear connectors for composite beams was conducted stud.

In this study, a model of efficient numerical simulation using the finite element method for laying out tests have been proposed. The model was validated against experimental results and with common standards such as BS5950 and the information given in EC4 and AISC were compared. By a number of researchers based on laboratory analysis and numerical research has been done on shear connectors, length, maximum width of cracks in concrete was found to be reduced. Lam and colleagues in 2005 studied pull tests on 12 samples of pre-fabricated hollow concrete slab, the scale is complete. In another work by Lam and El-Lobody (2005) new work has been developed to FEM modeling computational which has been obtained from experimental results which have been discussed in terms of accuracy. Comparison has been made on the conducted data and the results show good correlation between the finite element model from environmental point of view. In this study, the flexural behavior of steel beams embedded in concrete under static loads is investigated for sustainable environmental development.

\section{STATEMENT OF THE PROBLEM}

Full of strength, using techniques to enhance the capacity of these members is very important. Capacity is up against loads of material to be used simultaneously and efficiently.

\section{MODELINGALMAN LIMIT FOR CONSTITUENTS MERCURY COMPOUND}

In this article for a sample configuration of a threedimensional finite element model is used. For concrete modeling of three-dimensional elements (C3D8R) that an 8-node elements with reduced integration is used. Similar elements are considered for modeling steel sections. For longitudinal reinforcement and stirrups of the beam elements (B31) is used.

\section{CONCRETE IN ABAQUS FINITE ELEMENT METHOD}

In this study, the method used for modeling concrete, Concrete Damaged Plasticity is the model. This model is based on the assumption of isotropic damage survey and design for use in concrete under different environmentalloading conditions and the desired effect was accomplished. The embedded model is used for reinforcement.

\section{LOAD AND BOUNDARY CONDITIONS}

In the modeling study of rigid plates with a width of 10 $\mathrm{cm}$ was used as loading pages. Pages load and anchor tie in place by indicating that they have been fixed. Anchor plates on the boundary conditions with zero degrees of freedom U1 and U2 and UR2 and UR3 have taken place.

\section{MESHED MODEL}

Analysis of each of these models were calculated. By comparing the maximum load capacity for different meshing, percentage differences obtained for meshing

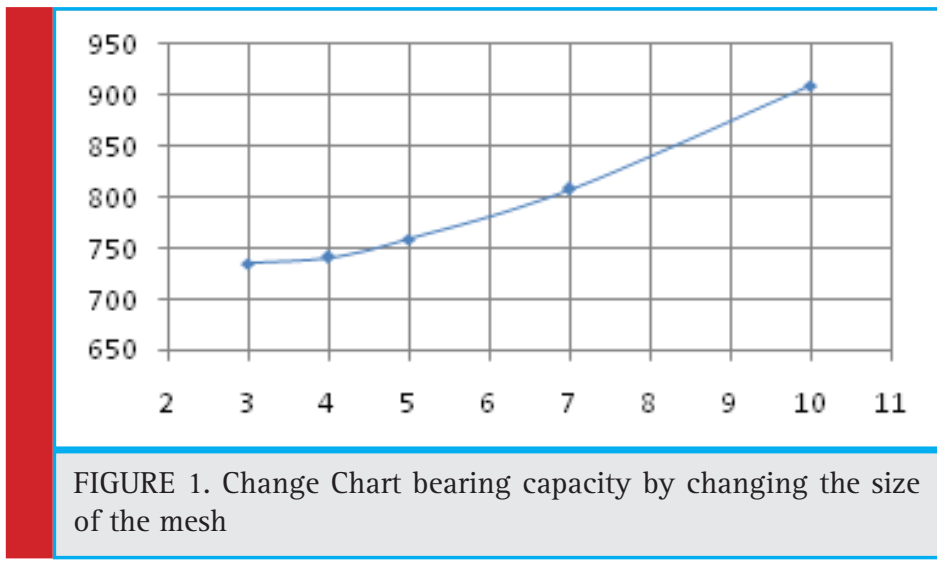




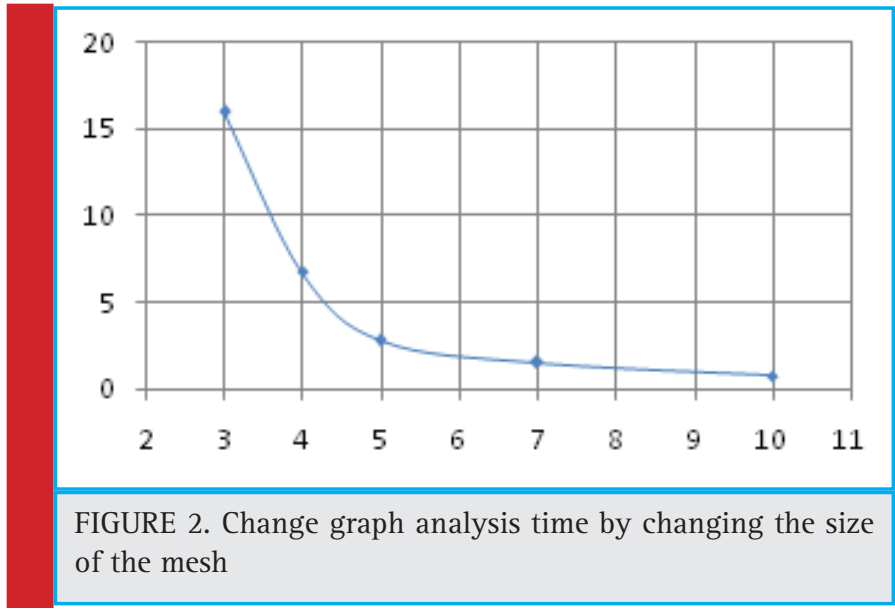

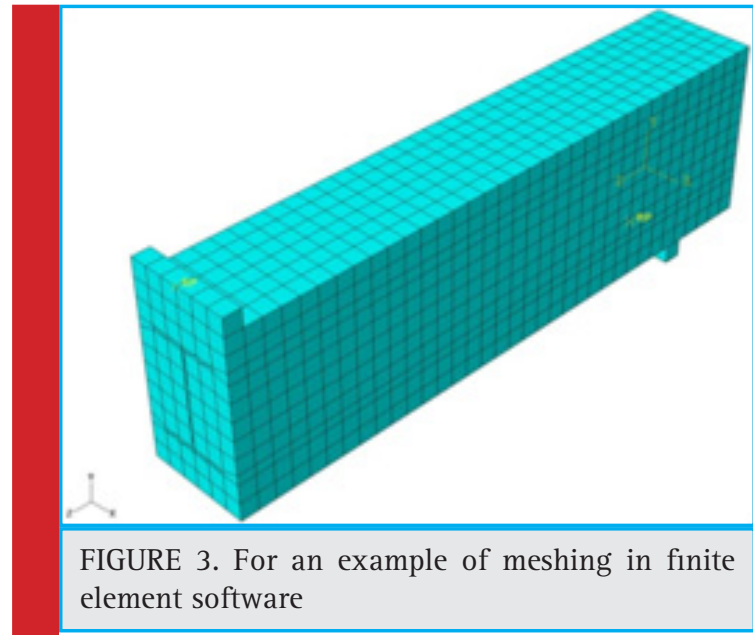

with meshing elements smaller than $5 \mathrm{~cm}$, less than $42 / 2$ percent is obtained. That's why the next 5 inches as the maximum size for meshing elements have been selected.

Extrusion method used to create pieces of concrete and steel beam is therefore for the mesh generator parts Swept meshing techniques are used. Elements used in the mesh of hexagonal Hex been selected. Seeded maxi- mum size of $5 \mathrm{~cm}$ is selected and used to control the curvature maximum deviation factor by default, the software is intended to 1/0. In Figure 3 meshed model for one of the samples shown.

\section{ANALYSIS MODEL}

Given the magnitude of the displacement and the need for non-linear analysis, dynamic methods for the analysis of selected models. The analytical method used in this study for explicit nonlinear dynamic analysis Dynamic Explicit is selected.

\section{THE IMPACT OF CHANGING THE ENTIRE WIDTH OF THE BEAM FLANGE WIDTH STEEL TOOLS}

One of the important parameters influencing the behavior of the composite beams of steel embedded in concrete, steel and concrete beam cross section Dimensions. the probability of failure is compounded in July.

Is. For this purpose, five different models, including models with wing width ratios $\mathrm{C} 1, \mathrm{C} 2, \mathrm{C} 3, \mathrm{C} 4$ and $\mathrm{C} 5$

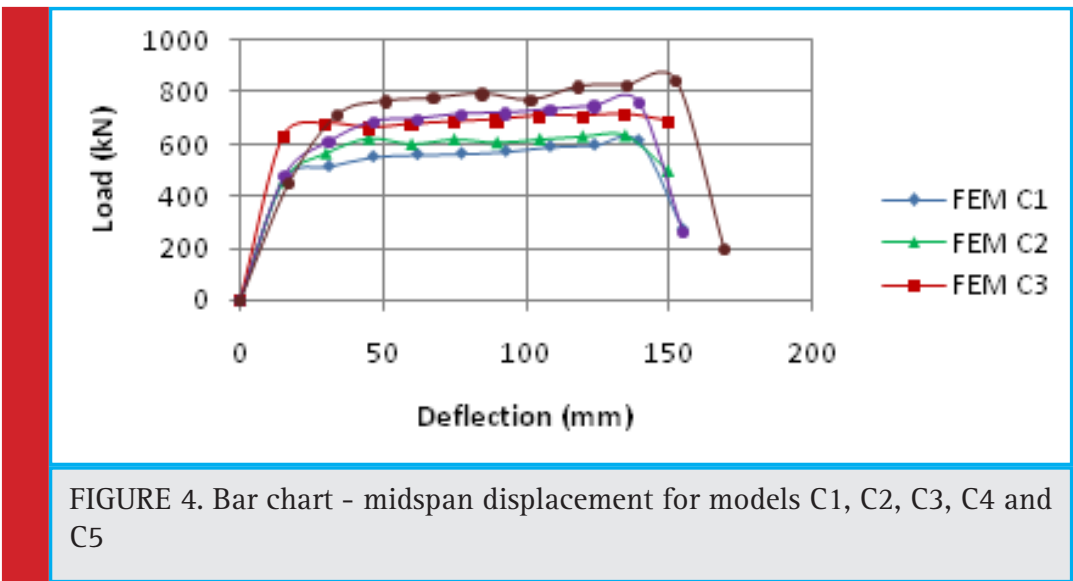






FIGURE 5. The graph ultimate bearing capacity for models C1, C2, C3, C4 and C5
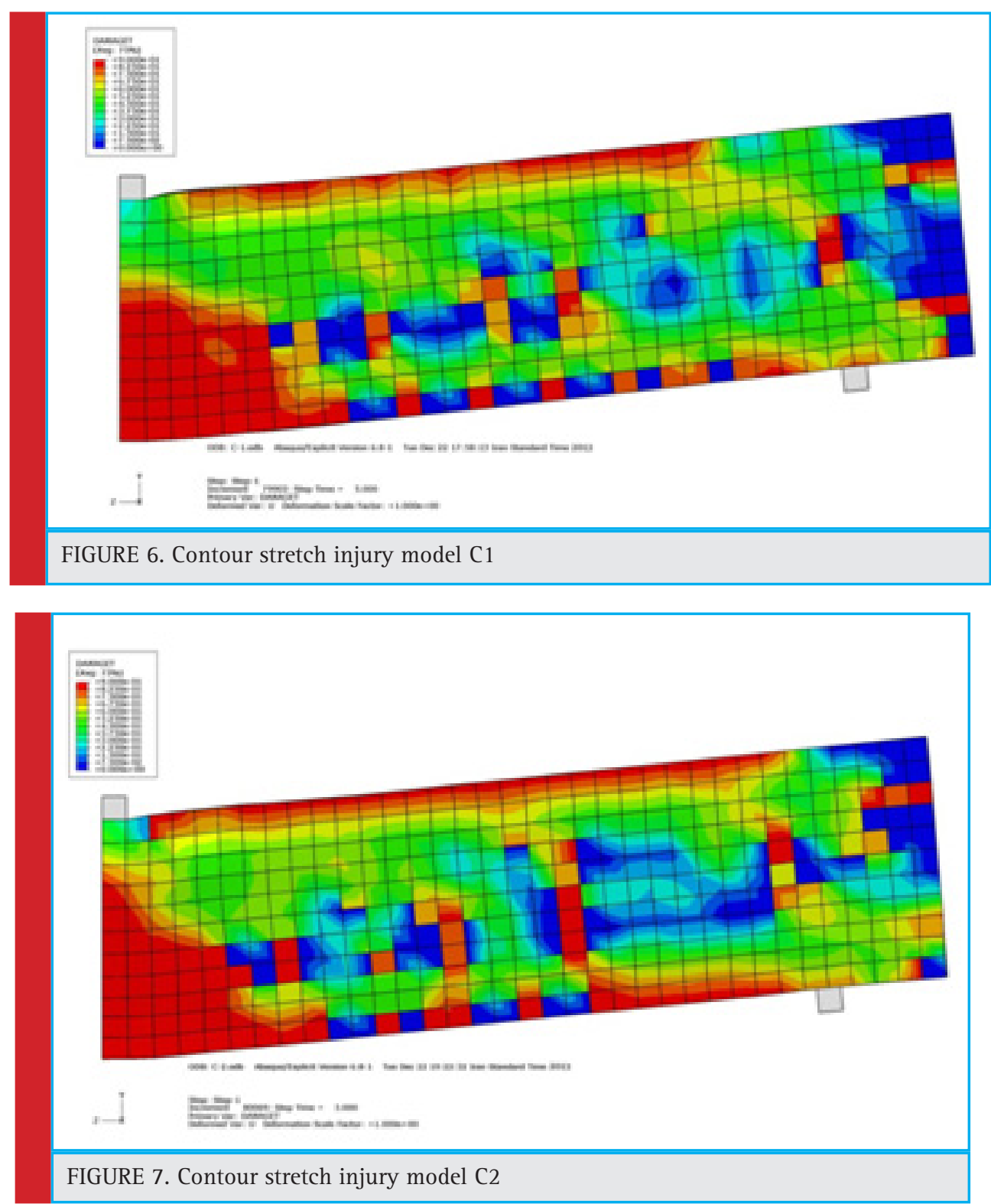


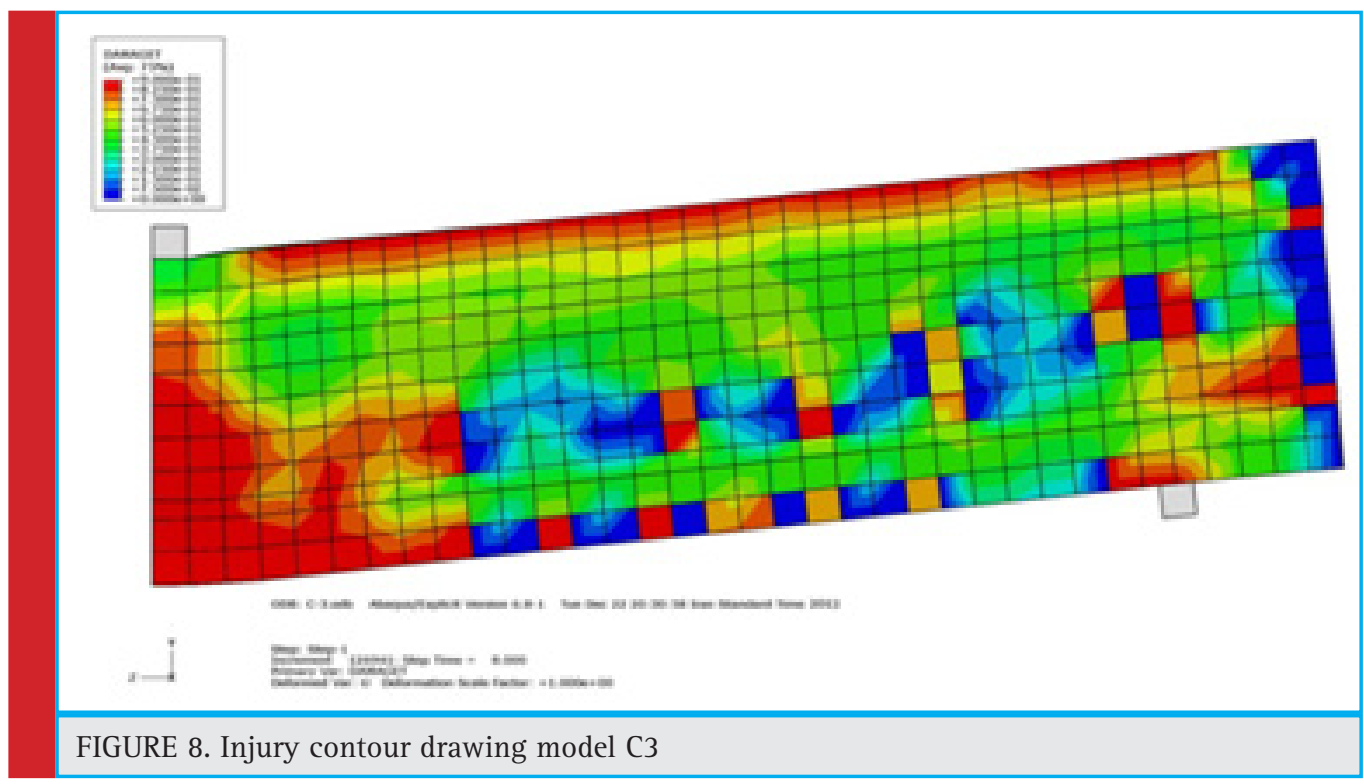

respectively steel with cross-sections of 120, 150, 180, 210 and $240 \mathrm{~cm}$ are selected.

All models have cross-sectional dimensions of 300 $\times 500 \mathrm{~mm}$, respectively. Longitudinal bars diameter 19 $\mathrm{mm}$ and diameter of $10 \mathrm{~mm}$ are inadequate. The distance of each other $150 \mathrm{~mm}$ is considered inadequate and has not been used in any of these models is cutting.

\section{GRAPHS TIME - DISPLACEMENT}

Bar graphs - C1 to C5 models displacement is presented in Figure 4. As the charts once - movement can be observed with increasing steel flange width, capacity, as well as the final beam forming compound has increased. Figure 5 shows the curve of the ultimate capacity models. According to this chart, the increase in capacity of $22.3 \%$ for the $\mathrm{C} 2$ than $\mathrm{C} 1$ models, for models from $\mathrm{C} 3$ to $\mathrm{C} 1$ model $37 / 16 \%, 91 / 23 \%$ and times for the $\mathrm{C} 4$ to $\mathrm{C} 1$ model to model C5 to C1 models from $94 / 37 \%$ is obtained.

\section{TENSILE CONTOURS INJURY}

In the form of (6) to (10) C1 to C5 models tensile injury contours are provided. With a little care can be noted that in models with smaller steel flange width, propagation of cracks at midspan is more considerable.

\section{RESHAPE THE CONTOURS OF PLASTIC}

Stickers (11) to (15) of plastic deformation contours C1 to $\mathrm{C} 5$ models for the show. three models have been predicted failure for shear.

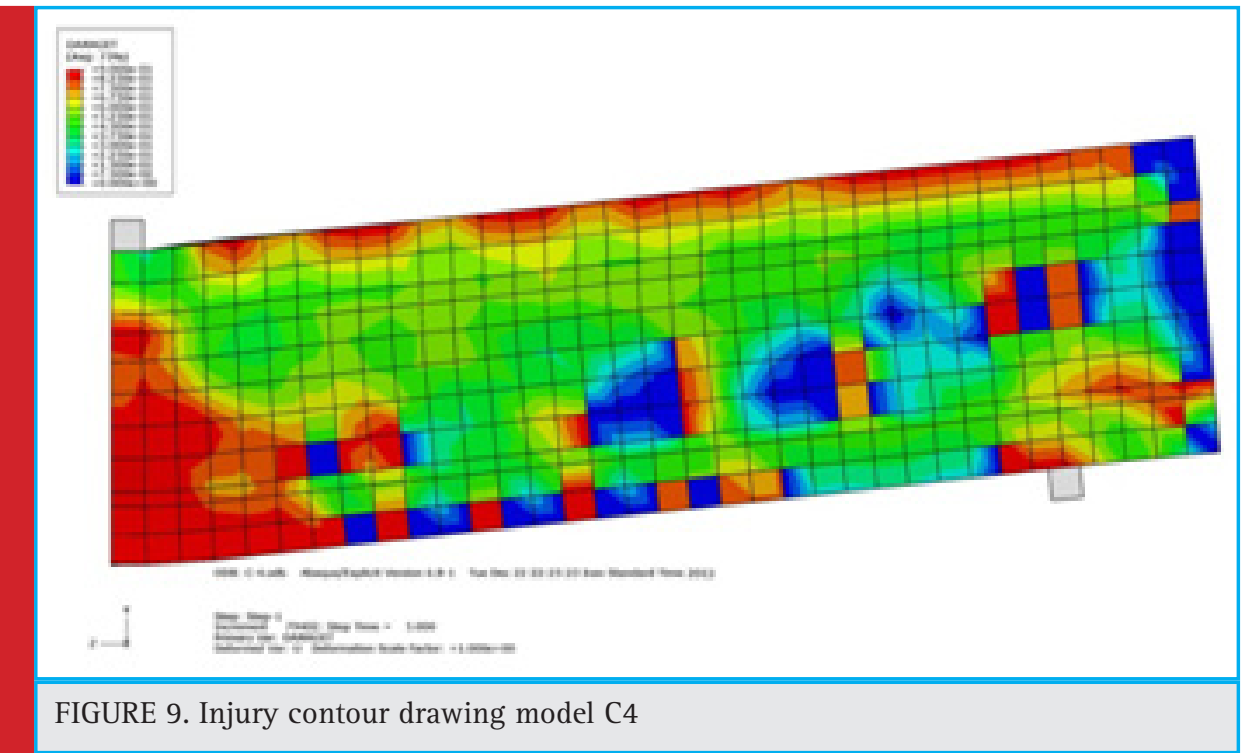




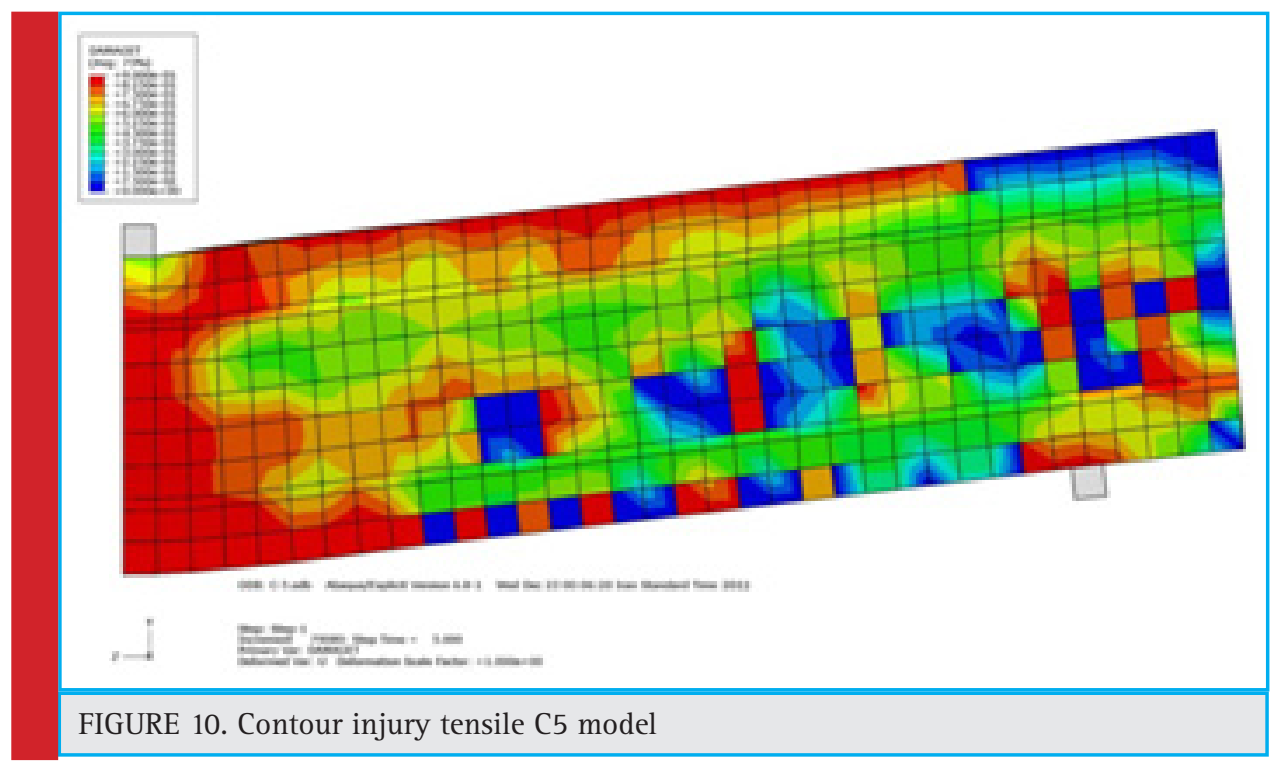

In Table 1. The results of the analysis and prediction models include the strength of the type of failure is presented. The finite element analysis results in compliance with Regulation Iran relations have been evaluated. According to a survey made very good match between the results of finite element analysis of the samples and relations are provided in the bylaws. The ultimate shear capacity of $353.8 \mathrm{kN}$ point in the relations of the Regulations is obtained. We see that in the $\mathrm{C} 1$ and $\mathrm{C} 2$ maximum shear force obtained from finite element analysis section is smaller than the shear capacity. Therefore, the models are broken due to reach its ultimate flexural capacity. Finite element analysis of bending failure for these models is the result. The results of finite element analysis also shows shear failure for these models.

\section{CONCLUSION}

In this article Environmental behavior of steel beams embedded in concrete under static loads were investigated. In contrast, in samples with a ratio of 0.5 steel flange width, usually bending failure have been observed. Results demonstrated that by optimizing the static load in the process of the production, the environmental side effects will be reduced and can be efficient in clean concrete production.

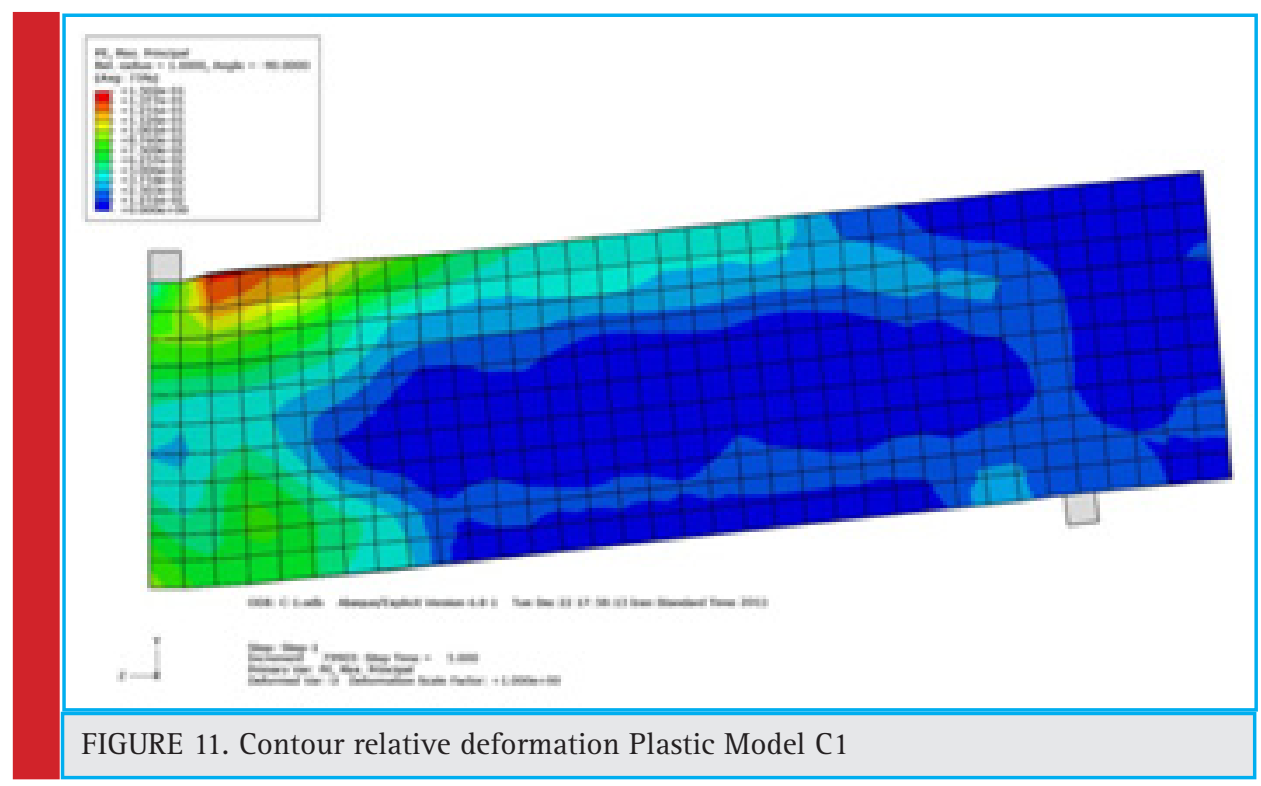


Bandehlou and Soltanabadi
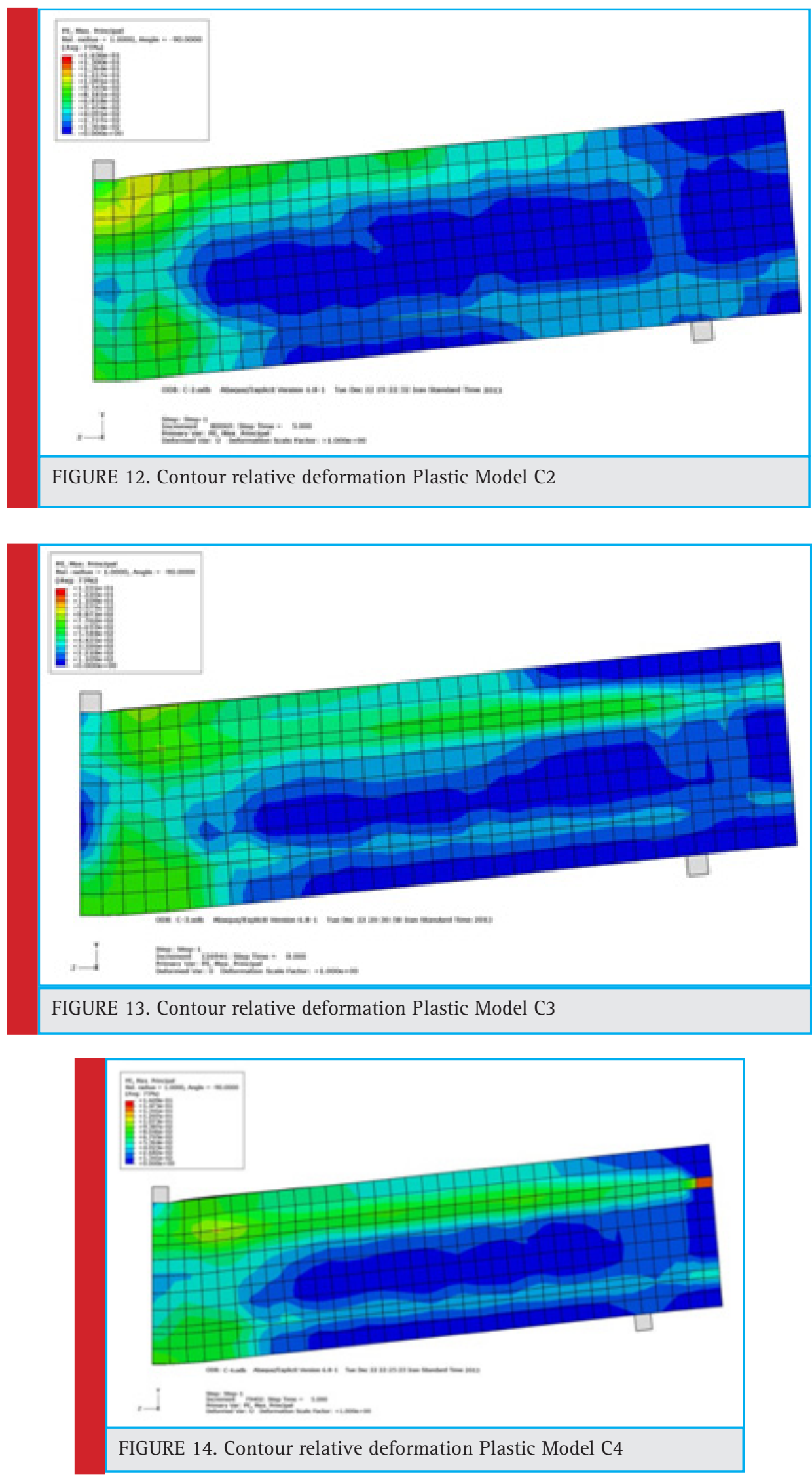


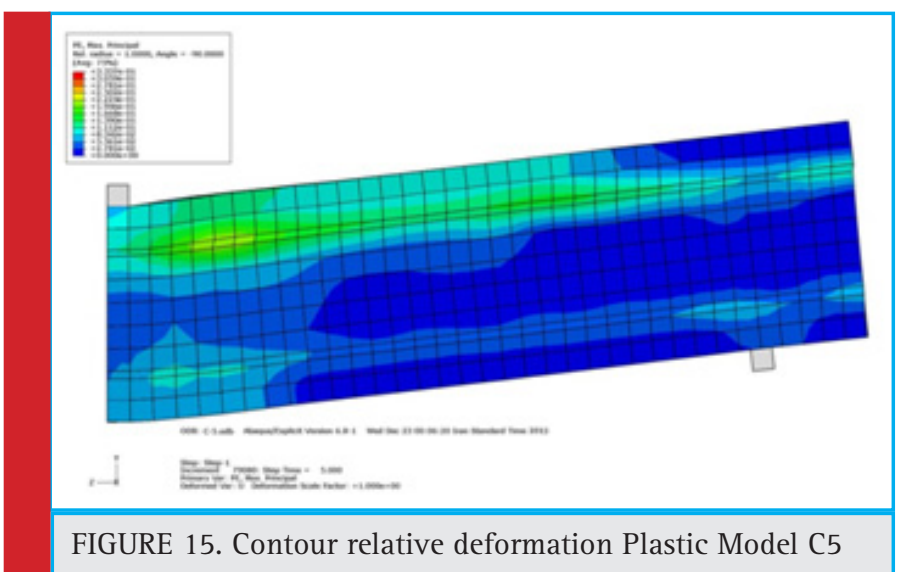

\begin{tabular}{|c|c|c|c|c|c|}
\hline \multirow{2}{*}{ Model } & \multirow{2}{*}{$\begin{array}{l}\text { Width } \\
\text { steel }\end{array}$} & \multirow{2}{*}{$\begin{array}{l}\text { Width } \\
\text { ratio }\end{array}$} & \multicolumn{2}{|c|}{ Resistance models } & \multirow{2}{*}{$\begin{array}{l}\text { The } \\
\text { type of } \\
\text { fracture }\end{array}$} \\
\hline & & & $\mathrm{V}(\mathrm{KN})$ & $\mathrm{M}(\mathrm{KN} \mathrm{m})$ & \\
\hline C1 & 120 & 0.4 & 306.5 & 459.8 & Bending \\
\hline $\mathrm{C} 2$ & 150 & 0.5 & 316.4 & 474.6 & Bending \\
\hline C3 & 180 & 0.6 & 356.7 & 535.1 & Bending \\
\hline C4 & 210 & 0.7 & 379.8 & 569.7 & Bending \\
\hline C5 & 240 & 0.8 & 422.8 & 634.2 & Bending \\
\hline
\end{tabular}

\section{REFERENCES}

Camps, B.; Baktheer, A.; Hegger, J.; Chudoba, R (2018). Experimental Characterization of Bond Fatigue Using Beam-End Tests with Push-In Loading. Proceedings 2, 417.

Ellobody, E. and Young, B. (2005) Performance of shear connection in composite beams with profiled steel sheeting," Department of Structural Engineering, Faculty of Engineering, Tanta University, Tanta, Egypt, Journal of Hydraulic Engineering, ASCE, Vol.132, No. 9, pp.971-982

Goldston, Matt \&t Remennikov, Alex \&t Sheikh, Md. (2016). Experimental Investigation of the Behaviour of Concrete Beams Reinforced with GFRP Bars under Static and Impact Loading. Engineering Structures. 113. 220-232. 10.1016/j.engstruct.2016.01.044.

Lam, D., El-Lobody, E. (2005) Behavior of Headed Stud Shear Connectors in Composite Beam School of Civil Engineering, University of Leeds, U.K., Journal of StructuralEngineering, Vol.131, No.1, pp. 96-107, 2005.

Liang, Q.Q., Uy, B., Bradford, A., and Ronagh, H.R. (2003) Ultimate strength of continuous composite beams in combined bending and shear, School of Civil and Environmental Engineering, The University of New South Wales, Sydney, Australia, Journal of Structural Engineering, Vol.131, No.10, pp.1593-1600

Mirza, S.A., Skrabek, B.W. (1991) Reliability of Short Composite Beam-Column Strength Interaction," Department of
Civil Engineering, University of Lakehead, Canada, Journal of Structural Engineering, Vol.117, No.8, pp.2320-2339

Nardin, S.D., El Debs, L.H.C. (2009) Study of partially encased composite beams with innovative position of stud bolts, Department of Structural Engineering, University of Sao Paulo at Sao Carlos, Sao Carlos, Brazil, Journal of Constructional Steel Research, Vol.65, No.2, pp.342-350

Ongpeng, J. M. C., Oreta, A. W. C., \&t Hirose, S. (2018). Investigation on the Sensitivity of Ultrasonic Test Applied to Reinforced Concrete Beams Using Neural Network. Applied Sciences, 8(3), 405.

Saadatmanesh, H., Albrecht, P., Ayyub, B.M. (1989) Guidelines for Flexural Design of Prestressed Composite Beams Civil. Engrg.andEngrg. Mech., University of Arizona, Journal of Structural Engineering, Vol.115, No.11, pp.29442961

Spacone, E., El-Tawil, S. (2004) Nonlinear Analysis of SteelConcrete Composite Structures Department of Civil Engineering, Department of Civil Engineering, University of Colorado, Journal of Structural Engineering, Vol.31, No.2, pp.523-533, 2004.

Zhao, G., Li, A. (2017) Numerical study of a bonded steel and concrete composite beam Laboratory of Mechanics, Materials and Structures, University of Reims Champagne Ardenne, France, Journal of Structural Engineering, Vol.86, No.19-20, pp.1830- 